International Journal of Education (IJE) Vol.6, No.3, September 2018

\title{
EFFECT OF EXTRINSIC MOTIVATION ON SECONDARY SCHOOL STUDENTS' ACADEMIC ACHIEVEMENT IN SOCIAL STUDIES
}

\author{
ODE, Dickson (Ph.D) \\ Wesley High School, Otukpo
}

\begin{abstract}
This study investigated the effect that extrinsically-motivated instructional method in collaboration with non extrinsically-motivated instructional method would have on secondary school students' academic achievement in social studies.. The post-test only experimental design was adopted. Two randomly selected junior secondary school II (JSS II) classes made up of 45 students each were divided into two groups (experimental group and control group) and investigated.Each of the two groups made up of 45 students was taught social studies for 9 weeks using extrinsically-motivated instructional method for the experimental group and non extrinsically-motivated instructional method for the control group. At the end of the 9th week, post-test was administered on the students to determine difference in academic achievement if any between the two groups. Using means and t-test in analyzing the data, the result showed that, students taught social studies using extrinsically-motivated instructional method significantly performed better than students taught social studies using non extrinsically-motivated instructional method. The study recommended among others that, teachers should always strive hard to apply available forms of extrinsic motivation in the instructional process to spur students to higher performance.
\end{abstract}

\section{KEYWORDS}

Extrinsic motivation, secondary school students, academic achievement, social studies

\section{INTRODUCTION}

In recent times, there has been much interest in respect of extrinsic motivation as it is generally believed to improve human performance in many spheres of life. Students as humans cannot be left out as to the effects of extrinsic motivation as they are likely to enjoy learning and show interest, value and dedicated effort towards achievement when motivated. This is in consonance with Quinis (2008) who stated that, students could be motivated to learn, almost anything if promised a sufficiently attractive external reward.

Rendering its perception as to what extrinsic motivation implies and its significance, Psychestudy.com (2018) stated that, extrinsic motivation refers to action or behaviour performed in the hopes of receiving an external reward or outcome. According to Psychestudy.com, extrinsic motivation could be used to motivate a whole group, thus increasing productivity in workplace or creating a better learning environment. Psychestudy.com also stated that, extrinsic motivation could lead to personal benefits. It (Psychestudy.com) added that, extrinsic motivation could lead to behaviour which could never have been possible otherwise. Psychestudy.com went further to explain its point by giving an example that, a student might never feel the intrinsic motivation to

DOI : 10.5121/ije.2018.6301 
study, but extrinsic motivations like medals or other forms of prize might motivate the student to study harder. The explanation provided by Psychestudy.com indicates that, from personal academic benefits, extrinsic motivation has economic advantage as it has the potential of stimulating productivity in the workplace.

Also, in the view of Meadows-Fernandez (2017), extrinsic motivation is reward driven behaviour. According to Meadows-Fernandez, extrinsic motivation, rewards or other incentives like praise, fame or money are used as motivation for specific activities. Meadows-Fernandez gave examples of extrinsic motivation which include competing in sports for trophies, completing work for money, customer loyalty discounts, buy one get one free sales, frequent flier rewards, helping people for praise from friends or family, doing work for attention, either positive or negative, doing task for public acclaim or fame, doing task to avoid judgment and completing coursework for grades. From the definition and examples of extrinsic motivation provided by MeadowsFernandez, it is understandable that, extrinsic motivation is either material or psychological in form. Meadows-Fernandez went further to stress on the need to motivate students.

According to Meadows-Fernandez, motivation will increase students' time on task and is also an important factor affecting their learning and achievement. The authority (Meadows-Fernandez) continued that, motivation enhances cognitive processing.

In unraveling the importance of extrinsic motivation, ConnectUS (2016) stated that, it drives a person to perform a task which ordinarily, he is not interested in as well as allows a person to set goals. In same vein, Rogers (2009) stated that, extrinsic motivation quickly changes behaviour, requires little effort or preparation and little knowledge of the student. Again, in unraveling the importance of extrinsic motivation, Borghans and Weel (2013) postulated that, it increases time investment and as a result, performance. In another effort to unfold the advantage of extrinsic motivation, Kuehn (2012) stated that, in generating enthusiasm or avidity for learning, a teacher must be a good motivator.

In a bid to uncover the meaning of extrinsic motivation, Cherry (2017) refers to it (extrinsic motivation $\}$ as behaviour that is driven by external rewards such as money, fame, grades and praise. Cherry explained that, extrinsic motivation occurs when we are motivated to perform a behaviour or an activity to earn a reward. Cherry gave examples of extrinsic motivation which include studying because, one wants to get good grade, cleaning the room to avoid being reprimanded by one's parents, participating in sports to win awards and competing in a contest to win scholarship.

In another effort to provide the meaning of extrinsic motivation, Cather (2015) stated that, it refers to taking some action in order to obtain a reward or outcome. Cather explained that, instead of doing something because it is fun, people who are extrinsically motivated act based on what they receive as a result. According to Cather, such people are not concerned with the action itself, but rather concerned only with the reward. Cather provided some examples of extrinsic motivation such as earning more education so that one can get paid more money and doing something in order to maintain self-esteem or pride or to avoid guilt or anxiety. 
Furthermore, in an effort to unfold the meaning of extrinsic motivation, Farlex Education Review (2018) stated that, it is the motivation directed toward the attainment of rewards that are separable from a behaviour or activity itself. In providing an explanation, Farlex Education Review stated that, it (extrinsic motivation) is an inducement to act or change based on the expectations and examples of other people. Farlex Education Review gave an example of extrinsic motivation such as an athlete who engages in sports just to win medals. From the definitions of extrinsic

motivation provided by the above authorities, it is clear that, extrinsic motivation is a behavour or action exhibited by an individual or group in the hope of getting a reward. Thus, the reward involved or given is geared towards increasing the psychological energy of the individual or group to perform.

From the above passages, it is ostensible that, extrinsic motivation is vital in the learning process. However, Yadav (2018, January 9th) and Hanson (2010) have expressed disgust that, in modern times, absence of extrinsic motivation from teachers has contributed to poor performance of students especially the unintelligent ones and subsequent dropping out of such students. According to Hanson, teachers are expected to inculcate into students the spirit of optimism and a sense of confidence in their dealings. In the view of Hanson, rather, unintelligent students are made fun of. According to Hanson, this (making fun of unintelligent students) kills the spirit of confidence and ultimately, the joy of attending school. Hanson continued that, in the end, the student drops out. In the same vein, Yadav (2018, Jan 8) stated that, encouraging students to ask questions and creating an environment for them to share their problems without any fear of being judged could liberate the students' thoughts and encourage them to be creative.

According to Yadav, a fearful mind blocks the learning and understanding capacity of students and consequently, performance of students decelerates. From the contributions of the above authorities, it is understandable that, when a lesson is devoid of motivation from the teacher, students' spirit to improve in learning is retarded or killed.

In trying to determine the effect of extrinsic motivation on learning, different studies carried out in the past had focused mainly on the science subjects with nothing on social studies. It is against this background that the researcher sought to investigate the effect that extrinsic motivation would have on secondary school students' academic achievement in social studies. Specifically, the study sought to investigate the effect that extrinsically-motivated instructional method (EIM) used in collaboration with non extrinsically-motivated instructional method (NEIM) would have on secondary school students' academic achievement in social studies.

\section{HYPOTHESIS}

The following hypothesis was tested at 0.05 level of significance in respect of the study.

There is no significant difference between the mean achievement scores of students taught social studies using non extrinsically-motivated instructional method and the students taught social studies using extrinsically-motivated instructional method at the secondary school level. 


\section{METHOD}

In the study, post-test only experimental design was employed with one experimental group (extrinsically-motivated instructional method) and one control group (non extrinsically-motivated instructional method). 90 junior secondary II students (JS II students) from a private secondary school in the North Central geo-political zone of Nigeria were used as subjects for the study. In the school where the study was carried out, there were four JS II classes. Using the simple random sampling technique, two JS II classes made up of 45 students each were selected with one class as experimental group and another as control group. The teacher-constructed instrument used in the study is called Social Studies Achievement Test (SOSAT). The test (SOSAT) consisted of 26 items which reflected the following main topics in JS II social studies syllabus: (i) physical environment, (ii) educational institutions and (iii) leadership, followership and

consequences. The 26 items in the SOSAT contained 20 multiple-choice and 6 essay type items based on the topics treated. The SOSAT was validated by one expert in social studies and one expert in measurement and evaluation. Using the Pearson Product Moment Correlation Coefficient, the reliability coefficient of SOSAT was 0.89 which indicated that, the instrument was reliable and appropriate for the study.

In line with the focus of the study, two teaching strategies were employed. They were: (i) extrinsically-motivated instructional method (EIM) and non extrinsically-motivated instructional method (NEIM). In the case of EIM, the instructional process was laden with rewards such as praise, applause, petty cash gifts as well as material gifts including biros, note books and foolscap sheets. As for the NEIM, the instructional process was devoid of any form of reward. It was the same experts that validated SOSAT that also validated EIM and NEIM.

In the investigation, both the experimental and control groups were respectively exposed to EIM and NEIM. The study lasted for 9 weeks. At the end of the 9th week of the study, the SOSAT was administered on the students. In analyzing the data for the post-test, the t-test statistics was applied.

\section{RESULTS}

Table 1: t-test analysis of the effect of extrinsically-motivated instructional method on achievement scores of students in social studies

\begin{tabular}{|c|c|c|c|c|c|c|}
\hline Treatment & $\mathrm{N}$ & Mean & $\begin{array}{l}\text { Std. } \\
\text { Deviation }\end{array}$ & $\mathrm{df}$ & $\mathrm{T}$ & $\mathrm{Sig}$ \\
\hline EIM & 45 & 76.42 & 14.33 & 88 & 8.106 & .000 \\
\hline NEIM & 45 & 56.35 & 8.16 & & & \\
\hline
\end{tabular}

Table 1 reveals that, the mean achievement score of students taught social studies using extrinsically-motivated instructional method (EIM) is 76.42 with a standard deviation of 14.33 
while those who were taught social studies using non extrinsically-motivated instructional method (NEIM) had mean achievement score of 56.35 with a standard deviation of 8.16. This shows that students who were exposed to extrinsically-motivated instructional method had higher mean achievement score than those exposed to using non extrinsically-motivated instructional method. Besides, the result shows that the calculated $t$ (8.106) for the effect of extrinsicallymotivated instructional method on achievement scores of students in social studies had an associated probability value of 0.000 . Since the probability value of 0.000 is less than the 0.05 level of significance, the null hypothesis was rejected. This implies that there is a significant difference in the mean achievement scores of students taught social studies using non extrinsically-motivated instructional method and the students taught social studies using extrinsically-motivated instructional method.

\section{DISCUSSION}

The findings of the study revealed that, there was significant difference in the mean achievement scores of students taught social studies using non extrinsically-motivated instructional method and the students taught social studies using extrinsically-motivated instructional method. This implies that, students exposed to extrinsically-motivated instructional method significantly performed better in social studies than students exposed to non extrinsically-motivated instructional method.

The above superior academic achievement discovered in the study could be due to the fact that, extrinsic motivation (rewards) helps to increase the psychological energy of the individual to perform. Thus, the individual is eager to perform well in order to attract rewards. This superior achievement due to the use of extrinsic motivation is in consonance with the findings of Ayub (2010) who found that, extrinsic motivation and academic performance were positively correlated.

\section{CONCLUSION}

Based on the findings of the study, it was concluded that, the use of extrinsic motivation in the instructional process enhances higher academic achievement in social studies among students. The study further revealed that, there was significant difference between the mean achievement scores of students taught social studies using non extrinsically-motivated instructional method and those taught social studies using extrinsically-motivated instructional method.

\section{RECOMMENDATIONS}

- Teachers should always strive to apply available forms of extrinsic motivation in the instructional process to spur students to higher performance

- Each national Parent Teachers Association (PTA) of every secondary school should make it as a matter of priority to set aside or institute a fund that will enable individual schools 
to smoothly introduce, incorporate and sustain the use of rewards to enhance students' academic performance in all subjects.

- The concept of speech and prize giving day should be embraced by all secondary schools as the public acknowledgement of excellent students on such a day will actually spur other students to strive hard and perform to receive such recognition.

- Parents and guardians should on their parts always endeavour to reward their wards who perform well in promotion and certificate examinations as such gesture will help to promote better performance in subsequent examinations taken.

- The government should make it as a matter of priority to always provide token reward for the best graduating student of every secondary school to encourage other students strive towards excellent academic achievement needed to drive the development process of any nation.

\section{REFERENCES}

[1] Ayub, N. (2010). Effects of intrinsic and extrinsic motivations on academic performance.Pakistan Business Review, $8,363-372$

[2] Borghaus, 1. \& Well, B.T. (2013). The importance of intrinsic and extrinsic motivation for measuring IQ. Economies of Education Review. 34, 1-16

[3] Cather, W. (2015). Extrinsic motivation. Retrieved on from http://www.study.com.extrinsicmotiation

[4] Cherry, K. (2017). Extrinsic motivation. Retrieved from http://www.verywell.com/what-isextrinsic...

[5] ConnectUS (2016). Extrinsic motivation. Retrieved from http://www.connectusfund.org

[6] Farlex Education Review. (2018). Extrinsic motivation. Retrieved from http://www.medicaldictionary.com/extrins

[7] Hanson, A. E. (2010). Blame the teacher. Retrieved from http://www.modernghana.com/../blame

[8] Kuehn, R.P. (2017). Responsibilities of a teacher: developing the moral values of students. Retrieved from http://www.saopxbove.com/social issues/responsibilities of a teacher

[9] Meadows-Fernandez, R. (2017). Extrinsic motivation. Retrieved from http://www.com>health>ext

[10] Psychestudy.com (2018). Extrinsic motivation. Retrieved from http://www.psychestudy.com/generalmotivation/extra

[11]Quinis, G. (2008). Extrinsic motivation. Retrieved from http://www.frepatentonline.com/article/journal/instructionalPsychology 
International Journal of Education (IJE) Vol.6, No.3, September 2018

[12]Rogers, W. (2009). The role of motivation in behaviour change. ACSM Fitnes Journal,13 (1), 7.Retrieved from http://www.cft.vainderbilt,edu/yeaching/guides/interaction/motivationstuden/

[13] Yadav, L. K. (2018, January 9th). Empathy on the classroom: educators must close the gap.Himalyan Times,pp.5 Retrieved From

http://www.thehimalayantimes.cm/opinion/empathy 